\title{
A Copula-Based Method for Estimating Shear Strength Parameters of Rock Mass
}

\author{
Da Huang, ${ }^{1,2,3}$ Chao Yang, ${ }^{1}$ Bin Zeng, ${ }^{1}$ and Guoyang Fu ${ }^{4}$ \\ ${ }^{1}$ School of Civil Engineering, Chongqing University, Chongqing 400045, China \\ ${ }^{2}$ State Key Laboratory of Coal Mine Disaster Dynamics and Control, Chongqing University, Chongqing 400045, China \\ ${ }^{3}$ Key Laboratory of New Technology for Construction of Cities in Mountain Area, Ministry of Education, Chongqing 400045, China \\ ${ }^{4}$ School of Civil, Environmental and Mining Resource Engineering, The University of Western Australia, Crawley, \\ WA 6009, Australia
}

Correspondence should be addressed to Da Huang; dahuang@cqu.edu.cn

Received 14 June 2014; Revised 30 September 2014; Accepted 14 October 2014; Published 4 November 2014

Academic Editor: Xi Frank Xu

Copyright (C) 2014 Da Huang et al. This is an open access article distributed under the Creative Commons Attribution License, which permits unrestricted use, distribution, and reproduction in any medium, provided the original work is properly cited.

\begin{abstract}
The shear strength parameters (i.e., the internal friction coefficient $f$ and cohesion $c$ ) are very important in rock engineering, especially for the stability analysis and reinforcement design of slopes and underground caverns. In this paper, a probabilistic method, Copula-based method, is proposed for estimating the shear strength parameters of rock mass. The optimal Copula functions between rock mass quality $Q$ and $f, Q$ and $c$ for the marbles are established based on the correlation analyses of the results of 12 sets of in situ tests in the exploration adits of Jinping I-Stage Hydropower Station. Although the Copula functions are derived from the in situ tests for the marbles, they can be extended to be applied to other types of rock mass with similar geological and mechanical properties. For another 9 sets of in situ tests as an extensional application, by comparison with the results from Hoek-Brown criterion, the estimated values of $f$ and $c$ from the Copula-based method achieve better accuracy. Therefore, the proposed Copula-based method is an effective tool in estimating rock strength parameters.
\end{abstract}

\section{Introduction}

The shear strength parameters including friction coefficient $f$ (the tangent of friction angle $\varphi$ ) and cohesion $c$ are the most fundamental mechanical parameters for rock mass. They are of very high importance for stability evaluation and support design of rock mass in rock engineering, especially for landslide risk mitigation. Different approaches including laboratory tests, in situ tests, back analysis, and empirical equations can be used to estimate these strength parameters. In the laboratory tests, scale effects are involved since rock specimens are of small sizes $[1,2]$. The back analysis method is also recommended by $[3,4]$ the fact that it might be more reliable than laboratory or in situ test method. Some empirical equations between shear strength parameters and geological indices are widely used due to simplicity and practicality [5-13]. The empirical equations based on famous Hoek-Brown criterion are [13]

$$
\begin{aligned}
& f \\
& =\tan \left\{\sin ^{-1}\left[\frac{6 a m_{b}\left(s+m_{b} \sigma_{3 n}\right)^{a-1}}{2(1+a)(2+a)+6 a m_{b}\left(s+m_{b} \sigma_{3 n}\right)^{a-1}}\right]\right\}, \\
& c \\
& =\frac{\sigma_{c}\left[(1+2 a) s+(1-a) m_{b} \sigma_{3 n}\right]\left(s+m_{b} \sigma_{3 n}\right)^{a-1}}{(1+a)(2+a) \sqrt{1+6 a m_{b}\left(s+m_{b} \sigma_{3 n}\right)^{a-1} /(1+a)(2+a)}},
\end{aligned}
$$

where $m_{b}$ is a reduction of the rock material constant $m_{i}$ and obtained by

$$
m_{b}=m_{i} \exp \left(\frac{\mathrm{GSI}-100}{28-14 D}\right)
$$


where GSI is the Geological Strength Index and $D$ is a disturbance factor, depending on the degree of disturbance by which the rock mass has been subjected to blast damage and stress relaxation. The $D$ varies from zero for undisturbed in situ rock mass to 1 for very disturbed rock mass. $s$ and $a$ in (1) can be calculated by

$$
\begin{gathered}
a=\frac{1}{2}+\frac{1}{6}\left(e^{-\mathrm{GSI} / 15}-e^{-20 / 3}\right), \\
s=\exp \left(\frac{\mathrm{GSI}-100}{9-3 D}\right) .
\end{gathered}
$$

In (1), $\sigma_{c}$ is uniaxial compressive strength, $\sigma_{3 n}=\sigma_{3 \max } / \sigma_{c}$, and $\sigma_{3 \max }$ is the upper-limit value of confining stress discussed by Hoek et al. [13].

It is important to take full advantage of in situ test data in order to establish the correlativity between geological indices and mechanical parameters of rock mass. With regard to the correlativity of the above variables, an effective way is to establish their joint distribution function. The common statistical methods for obtaining joint distribution function of variables are generally based on two assumptions; that is, the variables have the same marginal distributions and follow the normal distribution [14]. However, rock mass parameters do not always follow the normal distribution especially as the number of samples is small [15]. With respect to small samples, normal information spread estimation method (NISEM) [15] is suitable. Meanwhile, Copula theory [1621] is a fairly effective method to establish the joint distribution function of nonnormal distribution variables. The advantages of Copula theory are that the marginal distributions and dependence structure of variables can be studied separately and the variables can follow any distributions. The Copula theory has been widely used in many fields such as insurance [16], finance [17], hydrology [18-20], and geotechnical/geological engineering [21].

In this paper, the correlations between the rock mass quality indices (i.e., rock quality designation (RQD), rock mass quality $(Q)$, and Rock Block Index (RBI)) and the shear strength parameters $(f$ and $c)$ are investigated based on the results of in situ direct shear tests at Jinping I-Stage Hydropower Station in China. It shows that $Q$ presents the strongest correlation with the shear strength parameters. Then, the joint distribution functions of $Q$ and $f, Q$ and $c$ are proposed based on Copula theory. By means of the functions and the given guarantee rates, the shear strength parameters can be estimated. Compared with those estimated by HoekBrown criterion, the estimated values using the proposed Copula-based method are closer to the in situ tests ones.

\section{Correlations between Rock Mass Quality Indices and Shear Strength}

2.1. In Situ Test Data. The Jinping Hydropower Station is located on the middle reach of the Yalong River, in Sichuan, China. It has a double-curvature arch dam with a height of $305 \mathrm{~m}$ and a total installed capacity of $3300 \mathrm{MW}[22,23]$.

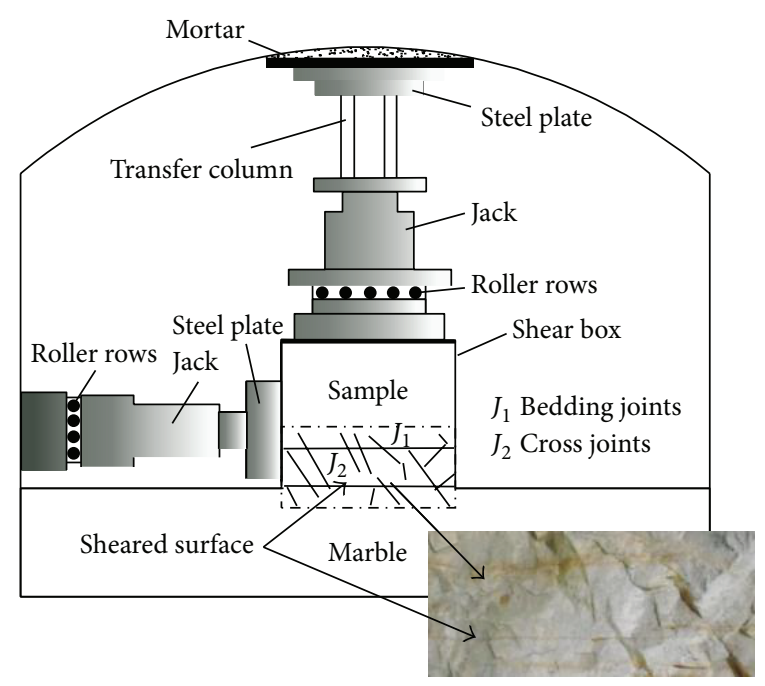

Figure 1: The sketch of the in situ direct shear test.

The Hydropower Station is located in the east edge of the Tibet Plateau tectonic belt. Due to the rapid crust uplift during the Quaternary, the steep slopes exist on both sides of the valley deeply cut by Yalong River. The stratum in the dam zone consists of a series of metamorphic rocks of middle of Triassic period, of which the great majority are marbles with grey or white and fine-grained texture. The main mineral compositions of the marble are calcite and dolomite. The uniaxial compressive strength of the fresh marble is about $60-$ $75 \mathrm{MPa}$.

In order to investigate the shear strength parameters of the representative marbles, 12 sets of in situ direct shear tests with five similar specimens in each set were performed in the exploration adits of Jinping I-Stage Hydropower Station. Figure 1 shows the sketch of in situ direct shear test which was performed using flat stacking method [24]. The side length of each cube specimen is $1 \mathrm{~m}$ which contains in general two sets of joints (bedding joints and cross joints; see Figure 1). RQD and RBI $[25,26]$ of each specimen can be obtained using scanline field mapping method. The scanline used for measuring RQD was parallel to shear direction. The shear direction was parallel to the bedding joint along which the shear deformation happened. The five similar specimens in a set were tested at different normal stress $\sigma_{n}$ from 2 to $10 \mathrm{MPa}$. The shear strength parameters $(f$ and $c$ ) of each set are obtained by linear regression according to Mohr-Coulomb criterion. A good fitting straight line between the peak shear stress $\tau$ and normal stress $\sigma_{n}$ can be derived from each set test data for which the $R^{2}$ of fitting degree is greater than 0.9 (see Figure 2). The test results are shown in Table 1, in which the rock mass quality indices are the average of each set samples, respectively.

2.2. Correlation Measure. Pearson linear correlation coefficient $\gamma_{n}$ [27], Spearman's rank correlation coefficient $\rho_{n}$ [28], and Kendall's rank correlation coefficient $\tau_{n}$ [29] are widely 


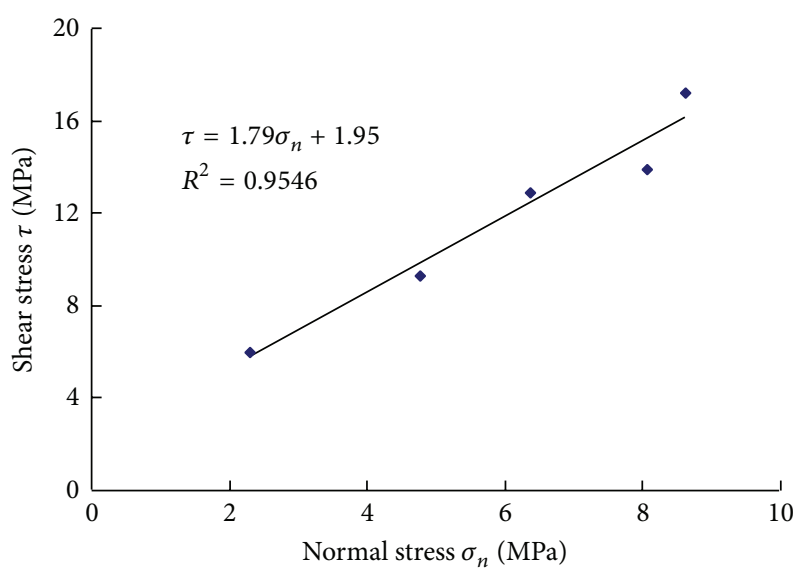

FIGURE 2: Linear regression of normal stress $\sigma_{n}$ versus shear stress $\tau$ for set number 1 in Table 1.

TABLE 1: Results of in situ direct shear tests and rock mass quality indices of the specimens.

\begin{tabular}{lccccc}
\hline \multirow{2}{*}{$\begin{array}{l}\text { Set } \\
\text { number }\end{array}$} & \multicolumn{2}{c}{ Rock mass quality indices } & \multicolumn{2}{c}{$\begin{array}{l}\text { Shear strength } \\
\text { parameters }\end{array}$} \\
& RQD/\% & RBI & Q & $f$ & $c /$ MPa \\
\hline 1 & 75.3 & 17.6 & 30.5 & 1.79 & 1.95 \\
2 & 89.3 & 31.5 & 23.8 & 1.38 & 1.98 \\
3 & 96.8 & 41.6 & 38.7 & 1.17 & 1.50 \\
4 & 99.3 & 31.8 & 39.7 & 2.20 & 2.25 \\
5 & 96.4 & 43.4 & 38.6 & 1.39 & 1.80 \\
6 & 98.1 & 22.6 & 26.5 & 1.60 & 1.80 \\
7 & 59.8 & 8.0 & 8.1 & 1.80 & 2.80 \\
8 & 56.0 & 10.3 & 5.2 & 1.17 & 1.20 \\
9 & 65.9 & 14.3 & 8.9 & 1.23 & 2.41 \\
10 & 77.4 & 13.2 & 5.2 & 0.56 & 3.00 \\
11 & 67.9 & 9.0 & 5.4 & 1.07 & 3.25 \\
12 & 51.8 & 7.0 & 4.6 & 1.15 & 4.32 \\
\hline
\end{tabular}

used to measure how relevant the variables are. They can be calculated by

$$
\begin{gathered}
\gamma_{n}=\frac{\sum_{i=1}^{n}\left(x_{1 i}-\overline{x_{1}}\right)\left(x_{2 i}-\overline{x_{2}}\right)}{n \sqrt{s_{1}^{2} \cdot s_{2}^{2}}}, \\
\rho_{n}=\frac{12}{n(n-1)(n+1)} \sum_{i=1}^{n} R_{i} S_{i}-3 \frac{n+1}{n-1}, \\
\tau_{n}=\left(\frac{n}{2}\right)^{-1} \sum_{i<j} \operatorname{sign}\left[\left(x_{1 i}-x_{1 j}\right)\left(x_{2 i}-x_{2 j}\right)\right],
\end{gathered}
$$

where $n$ is the number of observations, $x_{1 i}\left(x_{1 j}\right)$ and $x_{2 i}\left(x_{2 j}\right)$ are the observed values of variables $\left(x_{1}\right.$ and $\left.x_{2}\right), \overline{x_{1}}$ and $\overline{x_{2}}$ are sample mean, $s_{1}^{2}$ and $s_{2}^{2}$ are sample variance, $R_{i}$ and $S_{i}$ are the rank of $x_{1 i}$ and $x_{2 i}$, sign $=1$ if $x_{1 i}<x_{1 j}$ and $x_{2 i}<x_{2 j}$, and sign $=0$ if $x_{1 i}=x_{1 j}$ and $x_{2 i}=x_{2 j}$; otherwise, sign $=-1, i$, $j=1,2, \ldots, n$.

Table 2 shows the results of the $\gamma_{n}, \rho_{n}$, and $\tau_{n}$ of test data. There are clearly positive correlations (the same variation
TABLE 2: Correlation coefficients of the rock mass quality indices and the shear strength.

\begin{tabular}{lccc}
\hline Variables & Pearson $\gamma_{n}$ & Spearman $\rho_{n}$ & Kendall $\tau_{n}$ \\
\hline RQD- $f$ & 0.307 & 0.386 & 0.303 \\
RBI- $f$ & 0.241 & 0.376 & 0.303 \\
Q- $f$ & 0.550 & 0.656 & 0.545 \\
RQD- $c$ & -0.517 & -0.397 & -0.333 \\
RBI- $c$ & -0.573 & -0.635 & -0.515 \\
Q- $c$ & -0.563 & -0.517 & -0.485 \\
\hline
\end{tabular}

trend) between three rock mass quality indices (RQD, RBI, and $Q$ ) and $f$. The correlation coefficients between $Q$ and $f$ are much greater than those between RQD and $f, \mathrm{RBI}$ and $f$. There is clearly negative correlation (changes in the opposite trend) between the three indices and $c$. The correlation between RBI and $c$ is slightly better than $Q$ and $c$, while RQD and $c$ have the worst correlation. In summary, $Q$ has the best correlation with shear strength parameters $(f$ and c). In fact, RQD and RBI evaluate the rock mass quality only by the integrality of rock core. While many other factors, such as joint surface roughness and degree of weathering for dominantly oriented joint sets, joint water reduction, stress reduction factor, and volumetric joint count, are fully involved in Q-system, the Q-system, therefore, provides a comprehensive description on rock mass quality [30]. The shear strength parameters of jointed rock mass are generally controlled by complex geological conditions and mechanical behaviors of rock material and so on. The best correlation between $Q$ and the shear strength parameters in this statistical study also indicates that $Q$-system associated with multiple factors of influence on $c$ and $f$ of jointed rocks more precisely depicts the quality of rock mass.

The correlation measure indicates that, for the in situ tests presented in this paper, the marbles with higher rock mass quality indices show higher friction angle and lower cohesion. Many researchers had also found that, for rocks and soils, there was a negative correlation between $f$ and $c$ $[31,32]$. If this negative correlation is true between $f$ and $c$, it is easily understood that a variable has a positive correlation with one $(f)$ of shear strength parameters while a negative correlation must appear with the other $(c)$ based on the pure mathematical logic. As shown in Figure 1, there are some intact rock segments on the sheared bedding joint in the case of relatively low $Q$ value due to cross joint, which might explain why higher $Q$ has higher $f$ and lower $c$. The shear failure occurs along the weak bedding joint with a relatively low $c$ value on condition that the tested specimen has a high $Q$ value (good rock mass quality). When a low $Q$ value appears, these intact rock block segments on the shear surface must be thus cut through before reaching peak strength, which can increase the cohesion $c$ of the failure surface.

\section{Copula-Based Method}

3.1. Copula Theory. Considering multivariate random variables $X_{1}, \ldots, X_{i}, \ldots, X_{k}$ with marginal distribution functions 


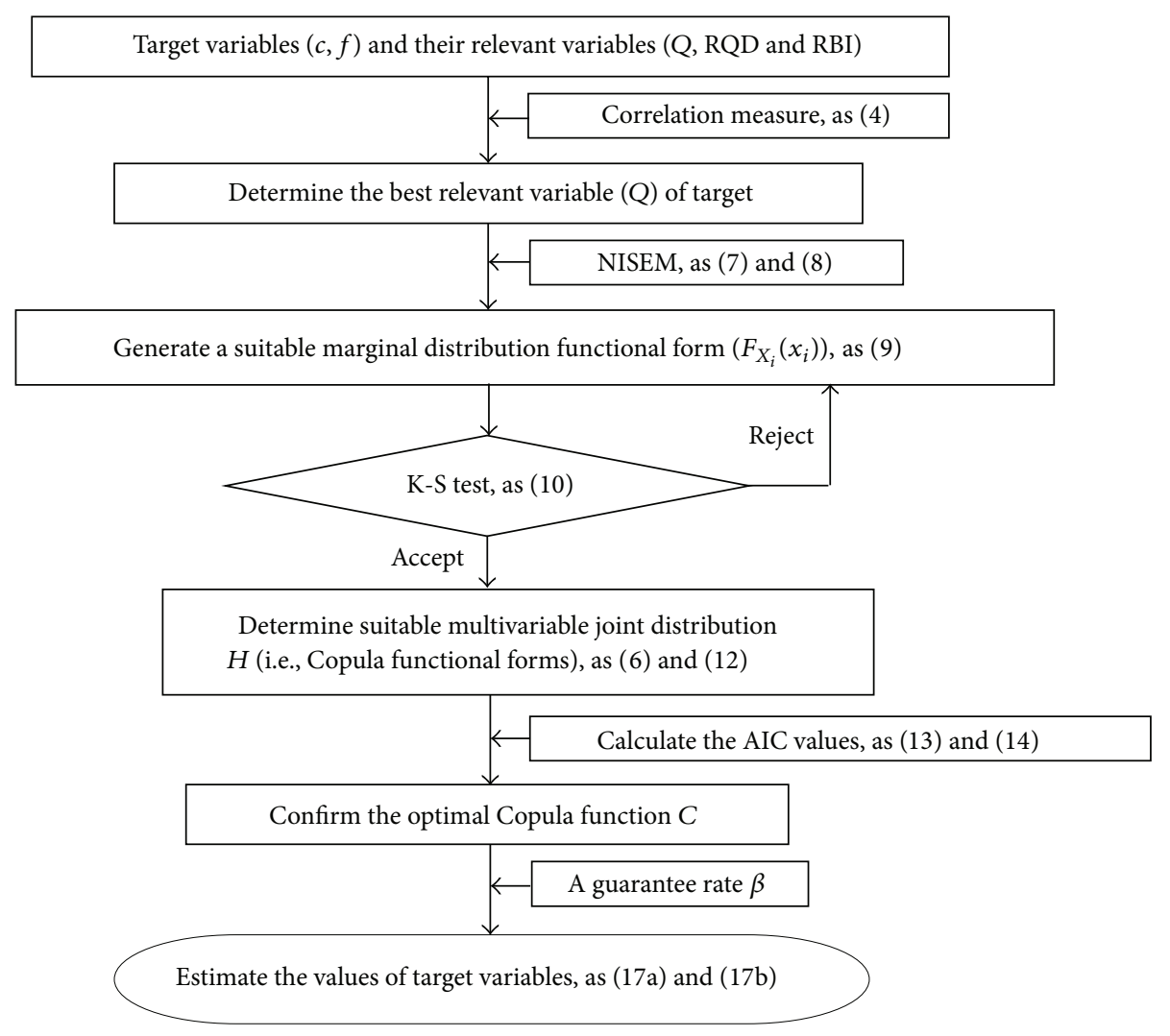

FIGURE 3: The calculation flow chart of Copula-based method.

as $F_{X_{i}}\left(x_{i}\right)=P_{X_{i}}\left(X_{i} \leq x_{i}\right)$, where $k$ is the number of random variables and $x_{i}$ is the value of random variable $X_{i}\left(X_{1}, \ldots, X_{i}, \ldots, X_{k}\right), F_{X_{i}}\left(x_{i}\right)$ is the marginal distribution function and $P_{X_{i}}\left(X_{i} \leq x_{i}\right)$ is the probability when $X_{i} \leq x_{i}$. The joint distribution function $H$ of the multivariate random variables $X_{1}, X_{2}, \ldots, X_{k}$ can been expressed as [33]

$$
\begin{aligned}
& H_{X_{1}, \ldots X_{i}, \ldots X_{k}}\left(x_{1}, \ldots, x_{i}, \ldots, x_{k}\right) \\
& \quad=P\left(X_{1} \leq x_{1}, \ldots, X_{i} \leq x_{i}, \ldots, X_{k} \leq x_{k}\right) .
\end{aligned}
$$

The Copula function is to connect multivariate probability distributions to their marginal probability distributions. Thus, the multivariate joint distribution $H$ is expressed in terms of its marginal distribution function $F_{X_{i}}\left(x_{i}\right)$ and the associated dependence structure $C$ as

$$
\begin{aligned}
& H_{X_{1}, \ldots X_{i}, \ldots X_{k}}\left(x_{1}, \ldots, x_{i}, \ldots, x_{k}\right) \\
& \quad=C\left(F_{X_{1}}\left(x_{1}\right), \ldots, F_{X_{i}}\left(x_{i}\right), \ldots, F_{X_{k}}\left(x_{k}\right)\right),
\end{aligned}
$$

where $C$, called Copula function, is a uniquely determined mapping whenever $F_{X_{i}}\left(x_{i}\right)$ are continuous and captures the essential features of the dependence between random variables. $C$ is essentially the joint distribution of multivariate random variables of $X_{1}, \ldots, X_{i}, \ldots, X_{k}$ through their marginal distributions $F_{X_{1}}\left(x_{1}\right), \ldots, F_{X_{i}}\left(x_{i}\right), \ldots, F_{X_{k}}\left(x_{k}\right)$ [33].

The joint distribution function established using Copulabased method has two major advantages: the marginal distribution and dependence structure can be studied separately, and the variables can follow any distributions. Therefore, the problem of determining $H$ reduces to determining marginal distribution of variables and Copula function $C$.

In order to clearly demonstrate the calculation procedure using the present Copula-based method, the calculation flow chart is shown in Figure 3. The detailed procedures are as follows.

Step 1. The correlation between target variables $(f, c)$ and relevant variables $(Q, R Q D$, and $R B I)$ is analyzed according to the correlation coefficients obtained by (4) or else. The best relevant variable (i.e., $Q$ ) can be selected, as shown in Section 2.2.

Step 2. Utilize suitable functional forms and methods (such as normal information spread estimation method (NISEM)) to establish marginal distribution function $F_{X_{i}}\left(x_{i}\right)$ of variables which could be accepted according to corresponding test (e.g., Kolmogorov-Smirnov (K-S) test). It is addressed in Section 3.2.

Step 3. Introduce suitable multivariable joint distribution functional forms (i.e., Copula functions) and confirm the optimal Copula function $C$ indicated by a minimum AIC value. Such is stated in Section 3.3.

Step 4. Estimate the values of target variables $(f, c)$ using the Copula method on condition that a guarantee rate $\beta$ and 
TABLE 3: Values of $\gamma$ for different values of $n$ [35].

\begin{tabular}{cccc}
\hline$n$ & $\gamma$ & $n$ & $\gamma$ \\
\hline 3 & 0.849321800 & 11 & 1.420835443 \\
4 & 1.273982782 & 12 & 1.420269570 \\
5 & 1.698643675 & 13 & 1.420698795 \\
6 & 1.336252561 & 14 & 1.420669671 \\
7 & 1.445461208 & 15 & 1.420693321 \\
8 & 1.395189816 & 16 & 1.420692226 \\
9 & 1.422962345 & 17 & 1.420693101 \\
10 & 1.416278786 & $>17$ & 1.420693101 \\
\hline
\end{tabular}

TABle 4: Values of $1 /(\sqrt{2 \pi} n h)$ and $1 / 2 h^{2}$.

\begin{tabular}{lcc}
\hline Variables & $1 /(\sqrt{2 \pi} n h)$ & $1 / 2 h^{2}$ \\
\hline RQD & 0.005420722 & 0.013293110 \\
RBI & 0.007073744 & 0.022636592 \\
$Q$ & 0.007335735 & 0.024344428 \\
$f$ & 0.157002612 & 11.15131578 \\
$c$ & 0.082527014 & 3.081091687 \\
\hline
\end{tabular}

the best relevant variable $Q$ have been given, which is presented in Section 4.

3.2. Verification of Marginal Distribution Functions. For small samples, the normal information spread estimation method (NISEM) [15] is an effective way to generate probability density functions. The main difference between NISEM and the available classical methods $[15,34]$ is that the variables are not assumed to follow a distribution (such as normal, log normal, and exponential distribution) in advance. It has been proved that the NISEM used for generating the probability density functions of geotechnical parameters with small samples is more accurate and effective than the other classical methods [15]. The probability density function of random variables $X_{i}$ by using NISEM is expressed as

$$
f\left(x_{i}\right)=\frac{1}{\sqrt{2 \pi} n h} \sum_{j=1}^{n} \exp \left[-\frac{\left(x_{i}-x_{i j}\right)^{2}}{2 h^{2}}\right],
$$

where $h$ is the window width of standard normal information spread function and $x_{i j}$ is the observed value of variable $X_{i}$. By the approaching principle of normal information diffusion, $h$ can be calculated by

$$
h=\frac{\gamma\left(x_{i \max }-x_{i \min }\right)}{n-1}
$$

where $x_{i \max }$ and $x_{i \min }$ are the maximal and minimum observed values of variable $X_{i}$. The value of $\gamma$ is related to $n$, as shown in Table 3 [35].

For the variables in Table $1, \gamma=1.420269570$ while $n=$ 12. Therefore, the estimation of probability density functions can be obtained from (7). The values of $1 /\left[(2 \pi)^{0.5} \mathrm{nh}\right]$ and $1 / 2 h^{2}$ (parameters of $f\left(x_{i}\right)$ ) are shown in Table 4.
TABLE 5: Results of Kolmogorov-Smirnov test.

\begin{tabular}{lccccc}
\hline Variables & $n$ & $\alpha$ & $D_{n, \alpha}$ & $D_{n}$ & $\begin{array}{c}\text { Accept or } \\
\text { reject }\end{array}$ \\
\hline RQD & 12 & 0.05 & 0.375 & 0.13617 & Accept \\
RBI & 12 & 0.05 & 0.375 & 0.09205 & Accept \\
$Q$ & 12 & 0.05 & 0.375 & 0.11670 & Accept \\
$f$ & 12 & 0.05 & 0.375 & 0.12352 & Accept \\
$c$ & 12 & 0.05 & 0.375 & 0.11224 & Accept \\
\hline
\end{tabular}

By means of the probability density functions $f\left(x_{i}\right)$ (see (7)), the marginal distribution functions $F_{X_{i}}\left(x_{i}\right)$ can be established as

$$
F_{X_{i}}\left(x_{i}\right)=\int_{-\infty}^{+\infty} f\left(x_{i}\right) d x_{i} .
$$

Kolmogorov-Smirnov (K-S) test commonly used to check whether a set of data follows a certain distribution [36] is adopted to test the established marginal distribution functions. The procedure of K-S test involves forming the cumulative frequency distribution $\widetilde{F}_{X_{i}}\left(x_{i}\right)$ and computing the test statistic $D_{n}$ :

$$
D_{n}=\max \left|F_{X_{i}}\left(x_{i}\right)-\widetilde{F}_{X_{i}}\left(x_{i}\right)\right| .
$$

The cumulative frequency distribution $\widetilde{F}_{X_{i}}\left(x_{i}\right)$ is defined as

$$
\widetilde{F}_{X_{i}}\left(x_{i}\right)=\frac{1}{n} \sum_{i=1}^{n} I_{x_{i j} \leq x_{i}}
$$

where $I_{x_{i j} \leq x_{i}}$ is the indicator function, equal to 1 if $x_{i j} \leq x_{i}$ and equal to 0 otherwise.

The established marginal distribution functions $F_{X_{i}}\left(x_{i}\right)$ will be accepted if $D_{n}<D_{n, \alpha}$, otherwise they will be denied. Where $D_{n, \alpha}$ is the critical value of a given significance level $\alpha$ (usually $\alpha=5 \%$ [37]), the $D_{n, \alpha}$ can be obtained using the table established by [38] when $n$ and $\alpha$ have been determined. Here, the significance level $\alpha$ is $5 \%$ and $n$ is 12 , so $D_{n, \alpha}=0.375$ based on the relevant table in [38]. The K-S test results are shown in Table 5. Obviously, all the established marginal distribution functions can be accepted.

3.3. Determination of the Optimal Copula Functions. In order to obtain the optimal Copula functions, the common method of the goodness-of-fit is adopted. Therefore, two steps are taken to determine the optimal Copula function: (1) selecting the suitably qualified Copula functions according to the characteristics of marginal distribution functions and dependent structure of variables and (2) determining the parameters of Copula functions selected.

With respect to two-dimensional Copula functions, the parameter $\theta$ of Copula functions can be obtained by means of Kendall's rank correlation coefficient $\tau_{n}$, which has been calculated in (4). The relation between $\tau_{n}$ and $\theta$ is [39]

$$
\tau_{n}=4 \int_{0}^{1} \int_{0}^{1} C\left(u_{i}, v_{i} ; \theta\right) d C\left(u_{i}, v_{i} ; \theta\right)-1,
$$




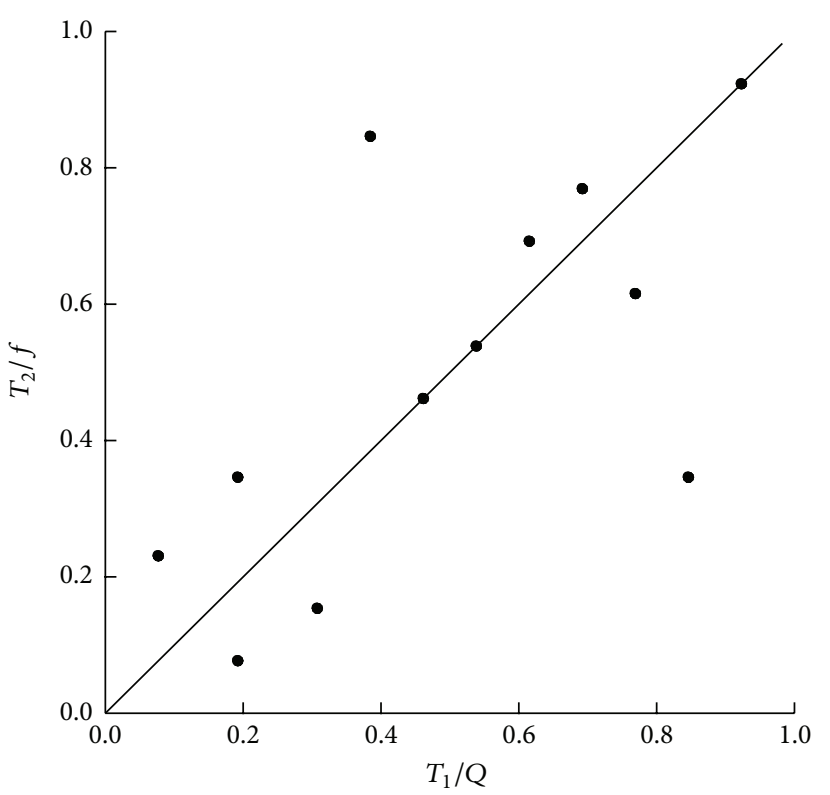

(a)

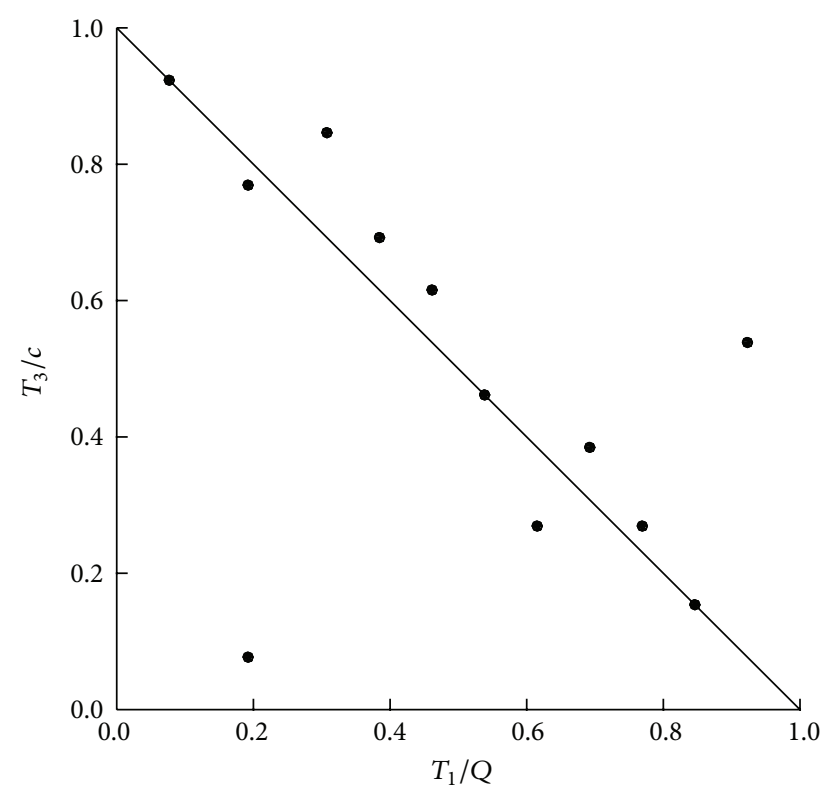

(b)

Figure 4: The scatter plots of empirical distribution: (a) $T_{1} / Q$ versus $T_{2} / f$ and (b) $T_{1} / Q$ versus $T_{3} / c$.

where $u_{i}$ and $v_{i}$ are the marginal distribution functional values on condition that the values of two variables are equal to $x_{1 i}$ and $x_{2 i}$ (i.e., $u_{i}=F_{X_{1}}\left(x_{1 i}\right)$ and $v_{i}=F_{X_{2}}\left(x_{2 i}\right)$ ), while $C\left(u_{i}, v_{i}, \theta\right)$ is the introduced Copula functional value with the parameter $\theta$.

Akaike information criteria (AIC) [40] are commonly used for goodness-of-fit test. AIC are based on entropy principle and are a simple and effective method for goodnessof-fit test [41]. And the optimal Copula is the one which has the minimum AIC value; the value of AIC can be calculated as

$$
\mathrm{AIC}=n \ln \left\{\frac{1}{n-t} \sum_{i=1}^{n}\left[F_{\mathrm{emp}}\left(x_{1 i}, x_{2 i}\right)-C\left(u_{i}, v_{i}\right)\right]^{2}\right\}+2 t,
$$

where $t$ is the number of parameters of Copula function $\left(t=1\right.$ for two-dimensional Copula function) and $C\left(u_{i}, v_{i}\right)$ is the Copula functional value. $F_{\text {emp }}\left(x_{1 i}, x_{2 i}\right)$ is the empirical probability functional value; it can be obtained as

$$
F_{\text {emp }}\left(x_{1 i}, x_{2 i}\right)=P\left(X_{1} \leq x_{1 i}, X_{2} \leq x_{2 i}\right)=\frac{1}{n+1} \sum_{j=1}^{n} \sum_{l=1}^{n} N_{j, l}
$$

where $N_{j, l}$ is the number of joint observations under the condition of $X_{1} \leq x_{1 i}$ as well as $X_{2} \leq x_{2 i}$.

In order to visualize the dependence structure of the measured data $\left(x_{1}, x_{2}\right)$ and to obtain an insight on a suitable Copula, the measured data in original space should be transformed into the standard uniform random vector $\mathbf{T}=$ $\left(T_{1}, T_{2}\right)$. Tang et al. [21] defined the random vector $\mathbf{T}$ by adopting the empirical distributions of measured data. $T_{1}$ and $T_{2}$ are expressed as

$$
\begin{aligned}
& t_{1 i}=\frac{\operatorname{rank}\left(x_{1 i}\right)}{n+1}, \\
& t_{2 i}=\frac{\operatorname{rank}\left(x_{2 i}\right)}{n+1},
\end{aligned}
$$

where $\operatorname{rank}\left(x_{1 i}\right)$ (or $\operatorname{rank}\left(x_{2 i}\right),\left(x_{3 i}\right)$ ) denotes the rank of $x_{1 i}$ (or $x_{2 i}, x_{3 i}$ ) among $x_{1}$ (or $x_{2}, x_{3 i}$ ) in an ascending order. $\left(t_{1 i}, t_{2 i}\right)$ are the values of variables $\left(T_{1}, T_{2}\right)$ or $\left(T_{1}, T_{3}\right)$ corresponding to $(Q, f)$ or $(Q, c)$.

The scatter plots of empirical cumulative distribution of $(Q, f)$ and $(Q, c)$ are shown in Figure 4. $Q$ and $f, Q$ and $c$ are substantially symmetric about the diagonal lines. Although the data points $(Q$ and $c$ ) in right Figure 4(b) seem to be not symmetric as well as those in left Figure 4(a), most of them are located around diagonal line (i.e., symmetrical line) in Figure 4(a). Archimedean Copulas have a wide range of application [19-21, 42] due to several competitive advantages: (1) the ease with which they can be constructed; (2) the great variety of families of copulas which belong to this class; and (3) the many nice properties possessed by members of this class [39]. As results, the symmetrical Archimedean Copulas, Nelsen No. 1, Nelsen No. 2, Nelsen No. 4, Nelsen No. 5, Nelsen No. 12, Nelsen No. 14, Nelsen No. 15, and Nelsen No. 18 [39] are selected to model the positive correlation between $Q$ and $f$, while Nelsen No. 1, Nelsen No. 2, Nelsen No. 5, Nelsen No. 7, Nelsen No. 8, and Nelsen No. 15 [39] are selected to model the negative correlation between $Q$ and $c$. By means of AIC calculated by (13), the goodness-of-fit test is used to determine the optimal Copula functions. The chosen symmetrical Archimedean Copula functions and the values of AIC are shown in Table 6. It shows that Nelsen No. 1 has 
TABLE 6: The parameter $\theta$ of 2D Copula functions and the values of AIC.

\begin{tabular}{|c|c|c|c|c|c|}
\hline Copula type & $C(u, v)$ & $\theta(Q-f)$ & $\operatorname{AIC}(Q-f)$ & $\theta(Q-c)$ & $\operatorname{AIC}(Q-c)$ \\
\hline Nelsen No. 1 & $\max \left[\left(u^{-\theta}+v^{-\theta}-1\right)^{-1 / \theta}, 0\right]$ & 2.396 & -67.990 & -0.653 & -61.777 \\
\hline Nelsen No. 2 & $\max \left\{1-\left[(1-u)^{\theta}+(1-v)^{\theta}\right]^{1 / \theta}, 0\right\}$ & 4.396 & -19.240 & 1.347 & -66.184 \\
\hline Nelsen No. 4 & $e^{-\left[(-\ln u)^{\theta}+(-\ln v)^{\theta}\right]^{1 / \theta}}$ & 2.198 & -66.341 & - & - \\
\hline Nelsen No. 5 & $-\frac{1}{\theta} \ln \left[1+\frac{\left(e^{-\theta u}-1\right)\left(e^{-\theta v}-1\right)}{e^{-\theta}-1}\right]$ & 4.978 & -65.175 & -5.442 & -59.637 \\
\hline Nelsen No. 7 & $\max [\theta u v-(1-\theta)(u+v-1), 0]$ & - & - & 0.634 & -44.658 \\
\hline Nelsen No. 8 & $\max \left[\frac{\theta^{2} u v-(1-u)(1-v)}{\theta^{2}-(\theta-1)^{2}(1-u)(1-v)}, 0\right]$ & - & - & 1.629 & -64.809 \\
\hline Nelsen No. 12 & $\left\{1+\left[\left(u^{-1}-1\right)^{\theta}+\left(v^{-1}-1\right)^{\theta}\right]^{1 / \theta}\right\}^{-1}$ & 1.465 & -67.648 & - & - \\
\hline Nelsen No. 14 & $\left\{1+\left[\left(u^{-1 / \theta}-1\right)^{\theta}+\left(v^{-1 / \theta}-1\right)^{\theta}\right]^{1 / \theta}\right\}^{-\theta}$ & 1.698 & -67.287 & - & - \\
\hline Nelsen No. 15 & $\max \left(\left\{1-\left[\left(1-u^{-1 / \theta}\right)^{\theta}+\left(1-v^{-1 / \theta}\right)^{\theta}\right]^{1 / \theta}\right\}^{\theta}, 0\right)$ & 2.698 & -65.360 & 1.173 & -60.240 \\
\hline Nelsen No. 18 & $\max \left\{1+\frac{\theta}{\ln \left(e^{\theta / u-1}+e^{\theta / v-1}\right)}, 0\right\}$ & 2.930 & -60.246 & - & - \\
\hline
\end{tabular}

the minimum AIC value for establishing the joint distribution function of $Q$ and $f$, while Nelsen No. 2 shows the minimum for that of $Q$ and c. Therefore, Nelsen No. 1 and Nelsen No. 2 can be used as the optimal Copula functions to construct the joint distribution functions $H$ of $Q-f$ and $Q-c$, respectively.

\section{Application to Estimating Shear Strength Parameters}

4.1. Guarantee Rate. Instability would happen if the strength parameters of rock mass are overvalued, while economic waste could be caused if they are undervalued. Assuming that the estimated values of shear strength parameters are $f_{1}$ and $c_{1}$, the actual values are $f$ and $c$; the guarantee rates $\beta_{f}$ and $\beta_{c}$ are then defined as the probability of $f>f_{1}$ and $c>c_{1}$, respectively, which can be expressed as

$$
\begin{gathered}
\beta_{f}=P\left(f>f_{1}\right), \\
\beta_{c}=P\left(c>c_{1}\right) .
\end{gathered}
$$

The estimated value is overvalued if guarantee rates $\beta$ are low, while being undervalued if high. In consequence, the estimated values can be evaluated by means of the guarantee rates $\beta$. On the other hand, the estimated $f$ and $c$ with a certain guarantee rates $\beta$ can be calculated by solving the conditional probability of the optimal Copula functions. Based on the optimal Copula functions $C$ of $Q-f$ and $Q-c$ established in Section 3.3, $\beta_{f}$ and $\beta_{c}$ can be calculated as

$$
\begin{aligned}
\beta_{f} & =P\left\{f>f_{1} \mid Q=Q_{0}\right\}=1-P\left\{f \leq f_{1} \mid Q=Q_{0}\right\} \\
& =1-C(U \leq u \mid V=v) \\
& =1-\lim _{\Delta v \rightarrow 0} \frac{C(u, v+\Delta v)-C(u, v)}{\Delta v} \\
& =1-\left.\frac{\partial}{\partial v} C(u, v)\right|_{v=v},
\end{aligned}
$$

$$
\begin{aligned}
\beta_{c} & =P\left\{c>c_{1} \mid Q=Q_{0}\right\}=1-P\left\{c \leq c_{1} \mid Q=Q_{0}\right\} \\
& =1-C(U \leq u \mid V=v) \\
& =1-\lim _{\Delta v \rightarrow 0} \frac{C(u, v+\Delta v)-C(u, v)}{\Delta v} \\
& =1-\left.\frac{\partial}{\partial v} C(u, v)\right|_{v=v},
\end{aligned}
$$

where $Q_{0}$ is the measured value of $Q$.

For direct shear test, in general, the predominant slope method and the least square method [43] are used to statistically process the test data. Using the least square method, the best linear fitting relations of normal stress $\sigma_{n}$ and shear stress $\tau$ for each class of rock mass quality are obtained, and the slope of fitting straight line is $f$, and the intercept at $\sigma_{n}$ axial is $c$ based on Mohr-Coulomb criterion. The predominant slope method is obviously different from the least square method although they are all based on Mohr-Coulomb criterion and linear fitting method. For the predominant slope method, the upper- and lower-limit values of cohesion $c$ should be conducted (Figure 5); the lower one is often suggested. Considering the obvious differences of $Q$ values in Table 1, 16 sets are grouped as Class II while 7-12 sets being grouped as Class III in rock mass quality. Their scatter plots of normal stress $\sigma_{n}$ versus shear stress $\tau$ are shown in Figure 5. The estimated results using the two methods are shown in Table 7.

As the prescribed standard [44] for the hydroelectric engineering in China, the suggested design parameters must have a guarantee rate $\beta$ of more than 0.8 . Therefore, it could be suggested that the $\beta$ of more than 0.95 are too high, while those of less than 0.20 are too low. Relative to the 12 sets test results in Table 1 , the guarantee rates $\beta_{f}$ and $\beta_{c}$ (by (17a) and (17b)) associated with the estimated $f$ and $c$ (in Table 7) are shown in Table 8. Most of them are not acceptable: all $\beta_{c}$ are too low using least square method, which means that the estimated $c$ are overvalued; the $\beta_{c}$ are larger than 0.95 for 


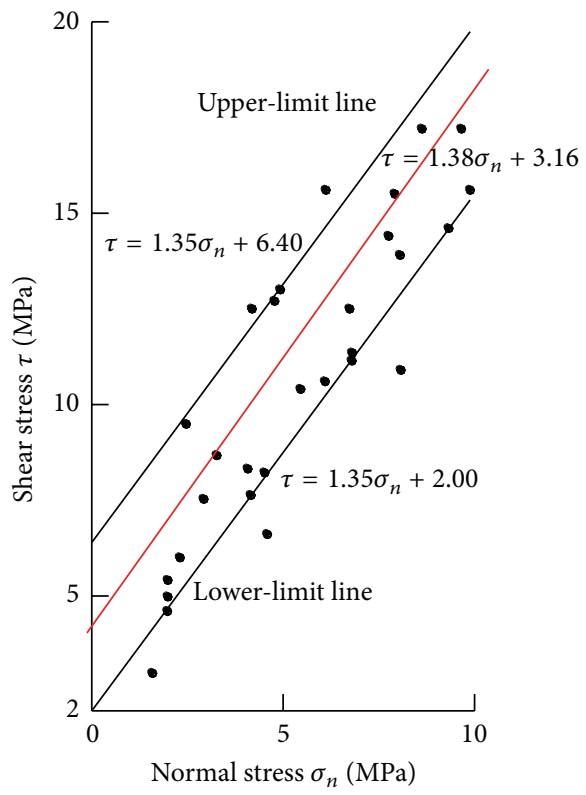

(a)

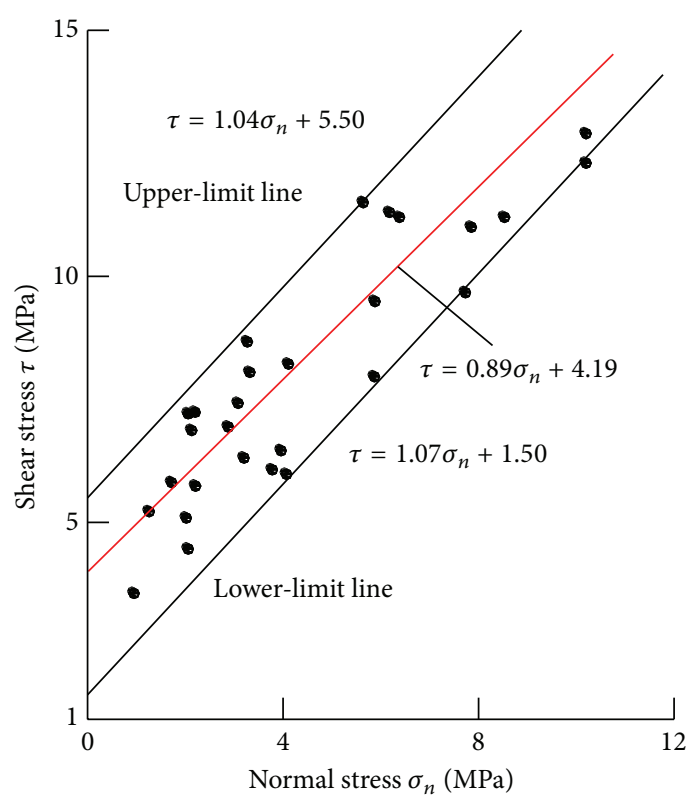

(b)

FIgure 5: The scatter plots of $\sigma_{n}$ versus $\tau$ : (a) Class II and (b) Class III.

TABLE 7: The estimated values of $f$ and $c$ using predominant slope and least square methods.

\begin{tabular}{lccccc}
\hline $\begin{array}{l}\text { Class of rock } \\
\text { mass quality }\end{array}$ & $\begin{array}{c}\text { Set } \\
\text { number }\end{array}$ & \multicolumn{2}{c}{$\begin{array}{l}\text { Predominant } \\
\text { slope method }\end{array}$} & \multicolumn{2}{c}{ Least square method } \\
& & $f$ & $c$ & $f$ & $c$ \\
\hline II & $1-6$ & 1.35 & 2.00 & 1.38 & 3.16 \\
III & $7-12$ & 1.07 & 1.50 & 0.89 & 4.19 \\
\hline
\end{tabular}

TABLE 8: The guarantee rates of estimated $f$ and $c$ using the predominant slope and least square methods.

\begin{tabular}{lccccc}
\hline $\begin{array}{l}\text { Set } \\
\text { number }\end{array}$ & $Q$ & \multicolumn{2}{c}{$\begin{array}{l}\text { Predominant } \\
\text { slope method }\end{array}$} & \multicolumn{2}{c}{$\begin{array}{l}\text { Least square } \\
\text { method }\end{array}$} \\
& & $\beta_{f}$ & $\beta_{c}$ & $\beta_{f}$ & $\beta_{c}$ \\
\hline 1 & 30.5 & 0.762 & 0.397 & 0.721 & 0.037 \\
2 & 23.8 & 0.650 & 0.564 & 0.600 & 0.070 \\
3 & 38.7 & 0.857 & 0.187 & 0.828 & 0.013 \\
4 & 39.7 & 0.868 & 0.206 & 0.839 & 0.015 \\
5 & 38.6 & 0.857 & 0.209 & 0.827 & 0.015 \\
6 & 26.5 & 0.698 & 0.499 & 0.652 & 0.055 \\
7 & 8.1 & 0.796 & 0.963 & 0.963 & 0.054 \\
8 & 5.2 & 0.532 & 0.980 & 0.867 & 0.098 \\
9 & 8.9 & 0.834 & 0.957 & 0.971 & 0.046 \\
10 & 5.2 & 0.532 & 0.980 & 0.867 & 0.098 \\
11 & 5.4 & 0.557 & 0.979 & 0.879 & 0.094 \\
12 & 4.6 & 0.453 & 0.982 & 0.819 & 0.110 \\
\hline
\end{tabular}

7-12 sets using predominant slope method, which means that the estimated $c$ are too undervalued. The data points must be located around the fitted straight line as far as possible on account that the least square method focuses on the best linear fitting of normal stress $\sigma_{n}$ and shear stress $\tau$ (Figure 5), which can cause the relatively low guarantee rates $\beta$ defined as (17a) and (17b), while the data pairs of $\sigma_{n}$ and $\tau$ are above the lower-limit fitting line (Figure 5) when the lower-limit values are adopted using the predominant slope method, which can lead to the large guarantee rates $\beta$. Therefore, the guarantee rate of the value $c$ is low by the least square method but high by the predominant slope method.

\subsection{Estimated Shear Strength Parameters Using Copula-} Based Method. The Copula-based fitting formulas established above are based on the test data of the 12 sets before; therefore, these tested shear strength parameters cannot be used to examine the extensional suitability of the Copula function obtained. The additional in situ direct shear tests are thus performed for the other 9 sets of the marbles with similar properties to check the application of Copula-based method to estimating shear strength parameters of rock mass. The $Q$ and GSI of the tested samples are also investigated at the same time. The test results are shown in Table 9.

The estimated $f$ and $c$ using Copula-based method have the guarantee rate $\beta$ of 0.8 . The Hoek-Brown criterion (see (1) to (3), the disturbance factor $D=0$ ), as a comparative method, is also adopted to calculate shear strength parameters (in Figure 6). The indicator to assess the predicted suitability of Copula-based method and Hoek-Brown criterion is the root mean square errors (RMSE) obtained by

$$
\begin{aligned}
\operatorname{RMSE}_{f} & =\sqrt{\frac{1}{n} \sum_{i=1}^{n}\left(f_{i}-f_{i}^{\prime}\right)^{2}}, \\
\operatorname{RMSE}_{c} & =\sqrt{\frac{1}{n} \sum_{i=1}^{n}\left(c_{i}-c_{i}^{\prime}\right)^{2}},
\end{aligned}
$$




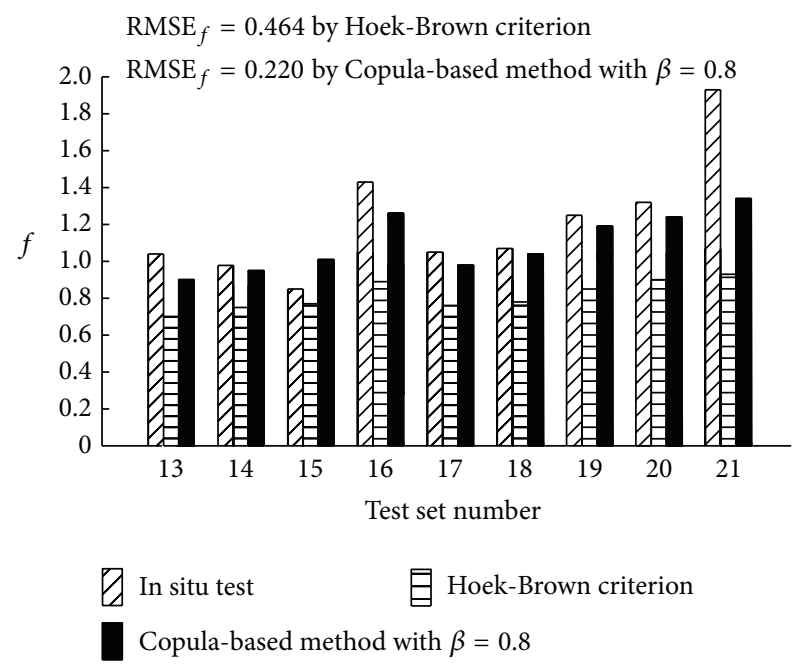

(a)

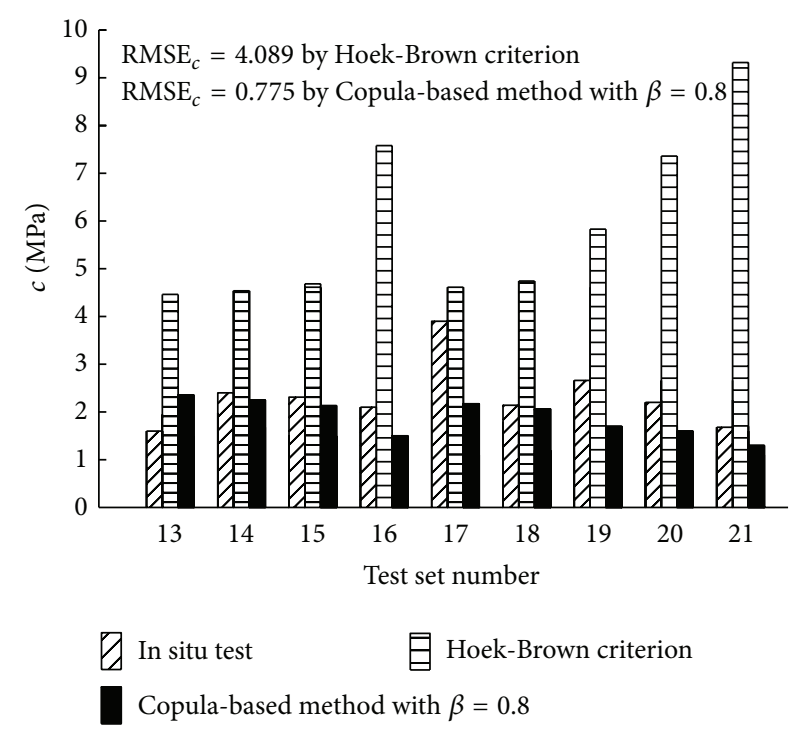

(b)

FIGURE 6: The shear strength parameters derived from Copula-based method and Heok-Brown criterion: (a) friction coefficient $f$ and (b) cohesion $c$.

TABLE 9: The results of other 9 sets of in situ direct shear tests.

\begin{tabular}{lcccc}
\hline $\begin{array}{l}\text { Set } \\
\text { number }\end{array}$ & \multicolumn{2}{l}{ Rock mass quality indices } & \multicolumn{2}{c}{ Shear strength parameters } \\
& $Q$ & GSI & $f$ & $c / \mathrm{MPa}$ \\
\hline 13 & 4.7 & 57.8 & 1.04 & 1.6 \\
14 & 5.3 & 59.6 & 0.98 & 2.4 \\
15 & 6.7 & 61.5 & 0.85 & 2.31 \\
16 & 25.4 & 75.8 & 1.43 & 2.1 \\
17 & 6.0 & 60.3 & 1.05 & 3.9 \\
18 & 7.3 & 62.1 & 1.07 & 2.14 \\
19 & 14.6 & 70.2 & 1.25 & 2.66 \\
20 & 23.4 & 76.3 & 1.32 & 2.2 \\
21 & 33.1 & 80.3 & 1.93 & 1.68 \\
\hline
\end{tabular}

where $f_{i}$ and $c_{i}$ are obtained from the in situ shear test and $f_{i}^{\prime}$ and $c_{i}^{\prime}$ are derived from Copula-based method or HoekBrown criterion. Clearly, the smaller the RMSE is, the more suitable the estimated result is.

Figure 6 indicates that the estimated shear strength parameters by Copula-based method are closer to in situ test values than those by Hoek-Brown criterion for the rock mass specimens in Table 9, which means that the proposed Copula-based method would be a more effective tool in estimating shear strength parameters of the marbles involved in this paper. The Hoek-Brown criterion with a wide range of applications is empirically established on the basis of the test results of a large number of different types of rock mass; the calculated accuracies of $f$ and $c$ are however seriously affected by the uncertain test conditions of $\sigma_{3 n}$ (see (1)) and undetermined disturbance factor $D$ and so forth (see (1)-(3)) $[45,46]$. However, the optimal Copula-based fitting functions established in the paper are on the basis of probabilistic analysis on the in situ direct shear test results of the 12 sets of similar marbles under the same test conditions, which should show better estimations of shear strength parameters of the rock mass with similar geological and mechanical properties.

\section{Conclusion}

Using the proposed Copula-based method, the shear strength parameters with a given $\beta$ can be estimated provided that $Q$ has been obtained. The calculated guarantee rate $\beta$ can be also used to analyze the suitability of the estimated values from the statistical methods for direct shear test data (such as predominant slope method and the least square method). For the marbles tested in this paper, compared with Hoek-Brown criterion, the Copula-based method is a more effective tool in estimating shear strength parameters.

The paper only considers the relationships between two of the parameters. Actually, the Copula functions could be of multidimensions and can be used to evaluate the parameters related with multiple variables. Furthermore, the Copula functions can be used for reliability analysis of estimated rock mass parameters.

\section{Conflict of Interests}

The authors declare that there is no conflict of interests regarding the publication of this paper.

\section{Acknowledgments}

This study is supported by the National Natural Science Foundation of China (41172243 and 41472245) and the Fundamental Research Funds for the Central Universities (CDJZR12205501 and 106112014CDJZR200009). 


\section{References}

[1] H. Sonmez, C. Gokceoglu, H. A. Nefeslioglu, and A. Kayabasi, "Estimation of rock modulus: For intact rocks with an artificial neural network and for rock masses with a new empirical equation," International Journal of Rock Mechanics and Mining Sciences, vol. 43, no. 2, pp. 224-235, 2006.

[2] J. Shen, M. Karakus, and C. Xu, "A comparative study for empirical equations in estimating deformation modulus of rock masses," Tunnelling and Underground Space Technology, vol. 32, pp. 245-250, 2012.

[3] K. Zhang, P. Cao, and R. Bao, "Rigorous back analysis of shear strength parameters of landslide slip," Transactions of Nonferrous Metals Society of China (English Edition), vol. 23, no. 5, pp. 1459-1464, 2013.

[4] J.-H. Wu and P.-H. Tsai, "New dynamic procedure for backcalculating the shear strength parameters of large landslides," Engineering Geology, vol. 123, no. 1-2, pp. 29-147, 2011.

[5] E. Hoek, P. K. Kaiser, and W. F. Bawden, Support of Underground Excavations in Hard Rock, Balkema, Rotterdam, The Netherlands, 1995.

[6] M. Cai, P. K. Kaiser, H. Uno, Y. Tasaka, and M. Minami, "Estimation of rock mass deformation modulus and strength of jointed hard rock masses using the GSI system," International Journal of Rock Mechanics and Mining Sciences, vol. 41, no. 1, pp. 3-19, 2004.

[7] X.-L. Yang and J.-H. Yin, "Slope equivalent Mohr-Coulomb strength parameters for rock masses satisfying the Hoek-Brown criterion," Rock Mechanics and Rock Engineering, vol. 43, no. 4, pp. 505-511, 2010.

[8] B. Singh, M. N. Viladkar, N. K. Samadhiya, and V. K. Mehrotra, "Rock mass strength parameters mobilised in tunnels," Tunnelling and Underground Space Technology, vol. 12, no. 1, pp. 4754, 1997.

[9] M. Hashemi, S. Moghaddas, and R. Ajalloeian, "Application of rock mass characterization for determining the mechanical properties of rock mass: a comparative study," Rock Mechanics and Rock Engineering, vol. 43, no. 3, pp. 305-320, 2010.

[10] J. L. Justo, E. Justo, J. M. Azañón, P. Durand, and A. Morales, "The use of rock mass classification systems to estimate the modulus and strength of jointed rock," Rock Mechanics and Rock Engineering, vol. 43, no. 3, pp. 287-304, 2010.

[11] R. J. Watters, D. R. Zimbelman, S. D. Bowman, and J. K. Crowley, "Rock mass strength assessment and significance to edifice stability, Mount Rainier and Mount Hood, Cascade Range volcanoes," Pure and Applied Geophysics, vol. 157, no. 6-8, pp. 957-976, 2000.

[12] N. Barton, "Some new Q-value correlations to assist in site characterisation and tunnel design," International Journal of Rock Mechanics and Mining Sciences, vol. 39, no. 2, pp. 185-216, 2002.

[13] E. Hoek, C. Carranza-Torres, and B. Corkum, "Hoek-Brown failure criterion-2002 edition," in Proceedings of the 5th North American Rock Mechanics Symposium, vol. 1, pp. 267-273, Toronto, Canada, 2002.

[14] L. Zhang, Multivariate hydrological frequency analysis and risk mapping [Ph.D. thesis], The Louisiana State University and Agricultural and Mechanical College, Baton Rouge, La, USA, 2005.

[15] F. Gong, X. Li, and J. Deng, "Probability distribution of small samples of geotechnical parameters using normal information spread method," Chinese Journal of Rock Mechanics and Engineering, vol. 25, no. 12, pp. 2559-2564, 2006 (Chinese).
[16] A. J. Patton, "Modelling asymmetric exchange rate dependence," International Economic Review, vol. 47, no. 2, pp. 527556, 2006.

[17] J. C. Rodriguez, "Measuring financial contagion: a copula approach," Journal of Empirical Finance, vol. 14, no. 3, pp. 401423, 2007.

[18] J. T. Shiau, "Fitting drought duration and severity with twodimensional copulas," Water Resources Management, vol. 20, no. 5, pp. 795-815, 2006.

[19] F. Serinaldi, "Copula-based mixed models for bivariate rainfall data: an empirical study in regression perspective," Handbook of Financial Time Series, vol. 23, no. 5, pp. 767-785, 2009.

[20] S. Song and V. P. Singh, "Frequency analysis of droughts using the Plackett copula and parameter estimation by genetic algorithm," Stochastic Environmental Research and Risk Assessment, vol. 24, no. 5, pp. 783-805, 2010.

[21] X.-S. Tang, D.-Q. Li, G. Rong, K.-K. Phoon, and C.-B. Zhou, "Impact of copula selection on geotechnical reliability under incomplete probability information," Computers and Geotechnics, vol. 49, pp. 264-278, 2013.

[22] S. W. Qi, F. Q. Wu, F. Z. Yan, and H. X. Lan, "Mechanism of deep cracks in the left bank slope of Jinping first stage hydropower station," Engineering Geology, vol. 73, no. 1-2, pp. 129-144, 2004.

[23] N. W. Xu, C. A. Tang, L. C. Li et al., "Microseismic monitoring and stability analysis of the left bank slope in Jinping first stage hydropower station in southwestern China," International Journal of Rock Mechanics and Mining Sciences, vol. 48, no. 6, pp. 950-963, 2011.

[24] P. K. Robertson, "In situ testing and its application to foundation engineering," Canadian Geotechnical Journal, vol. 23, no. 4, pp. 573-594, 1986.

[25] A. Palmstrøm, "Characterizing rock masses by the RMi for Use in Practical Rock Engineering: Part 1: the development of the Rock Mass index (RMi)," Tunnelling and Underground Space Technology, vol. 11, no. 2, pp. 175-188, 1996.

[26] A. Palmstrøm, "Characterizing rock masses by the RMi for use in practical rock engineering, Part 2: some practical applications of the rock mass index (RMi)," Tunnelling and Underground Space Technology, vol. 11, no. 3, pp. 287-303, 1996.

[27] L. Legendre and P. Legendre, "Numerical ecology," in Developments in Environmental Modelling, Elsevier Scientific BV, Amsterdam, The Netherlands, 2nd edition, 1998.

[28] E. L. Lehmann, "Some concepts of dependence," The Annals of Mathematical Statistics, vol. 37, pp. 1137-1153, 1966.

[29] E. L. Lehmann, Nonparametrics: Statistical Methods Based on Banks Test, Holden-Day, San Francisco, Calif, USA, 1975.

[30] B. Singh and R. Goel, Engineering Rock Mass Classification: Tunnelling, Foundations and Landslides, EIsevier, 2011.

[31] G. Mollon, D. Dias, and A.-H. Soubra, "Probabilistic analysis of circular tunnels in homogeneous soil using response surface methodology," Journal of Geotechnical and Geoenvironmental Engineering, vol. 135, no. 9, pp. 1314-1325, 2009.

[32] H. F. Schweiger, R. Thurner, and R. Pöttler, "Reliability analysis in geotechnics with deterministic finite elements: theoretical concepts and practical application," International Journal of Geomechanics, vol. 1, no. 4, pp. 389-413, 2001.

[33] S. C. Kao and R. S. Govindaraju, "A copula-based joint deficit index for droughts," Journal of Hydrology, vol. 380, no. 1-2, pp. 121-134, 2010.

[34] J. Deng, X. B. Li, and G. S. Gu, "A distribution-free method using maximum entropy and moments for estimating probability curves of rock variables," International Journal of Rock 
Mechanics and Mining Sciences, vol. 41, supplement 1, pp. 1-6, 2004.

[35] X. Wang, Y. You, and Y. Tang, "An approach to calculate optimal window-width serving for the information diffusion technique," International Journal of General Systems, vol. 33, no. 2-3, pp. 223-231, 2004.

[36] F. A. Andrade, I. I. Esat, and M. N. M. Badi, "Gear condition monitoring by a new application of the Kolmogorov-Smirnov test," Proceedings of the Institution of Mechanical Engineers, Part C: Journal of Mechanical Engineering Science, vol. 215, no. 6, pp. 653-661, 2001.

[37] H. X. Chen, P. S. K. Chua, and G. H. Lim, "Fault degradation assessment of water hydraulic motor by impulse vibration signal with Wavelet Packet Analysis and Kolmogorov-Smirnov Test," Mechanical Systems and Signal Processing, vol. 22, no. 7, pp. 1670-1684, 2008.

[38] F. J. Massey, "The Kolmogorov-Smirnov test for goodness of fit," Journal of the American Statistical Association, vol. 46, no. 253, pp. 68-78, 1951.

[39] R. B. Nelsen, An instruction to Copulas, Springer, New York, NY, USA, 2006.

[40] H. Akaike, "A new look at the statistical model identification," IEEE Transactions on Automatic Control, vol. 19, no. 6, pp. 716723, 1974.

[41] N. Sugiura, "Further analysts of the data by akaike's information criterion and the finite corrections: further analysts of the data by akaike's," Communications in Statistics-Theory and Methods, vol. 7, no. 1, pp. 13-26, 1978.

[42] O. Okhrin, Y. Okhrin, and W. Schmid, "On the structure and estimation of hierarchical Archimedean copulas," Journal of Econometrics, vol. 173, no. 2, pp. 189-204, 2013.

[43] N. Barton, "Review of a new shear-strength criterion for rock joints," Engineering Geology, vol. 7, no. 4, pp. 287-332, 1973.

[44] Design Specification for Roller Compacted Concrete Dams, SL 314-2004, China Water \& Power Press, Beijing, China, 2004, (Chinese).

[45] E. Hoek, C. Carranza-torres, and B. Corkum, "Hoek-Brown failure criterion," in Proceedings of the NARMS-TAC Conference, pp. 267-273, Toronto, Canada, 2002.

[46] Y. H. Song and G. H. Ju, "Determination of rock mass shear strength based on in-situ tests and codes and comparison with estimation by Hoek-Brown criterion," Chinese Journal of Rock Mechanics and Engineering, vol. 31, no. 5, pp. 1000-1006, 2012 (Chinese). 


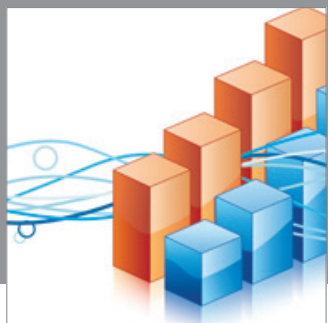

Advances in

Operations Research

mansans

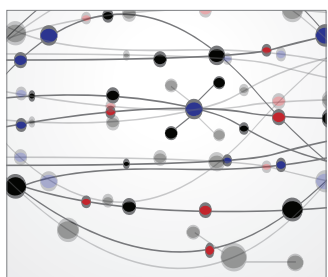

The Scientific World Journal
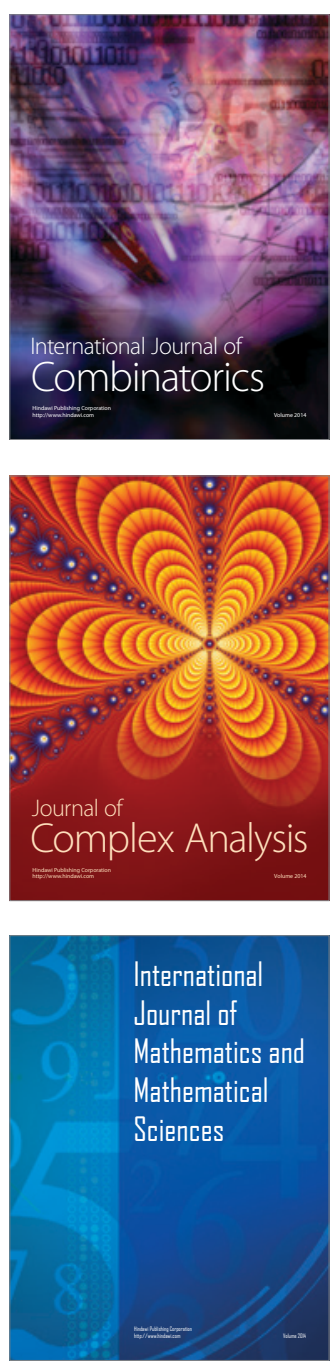
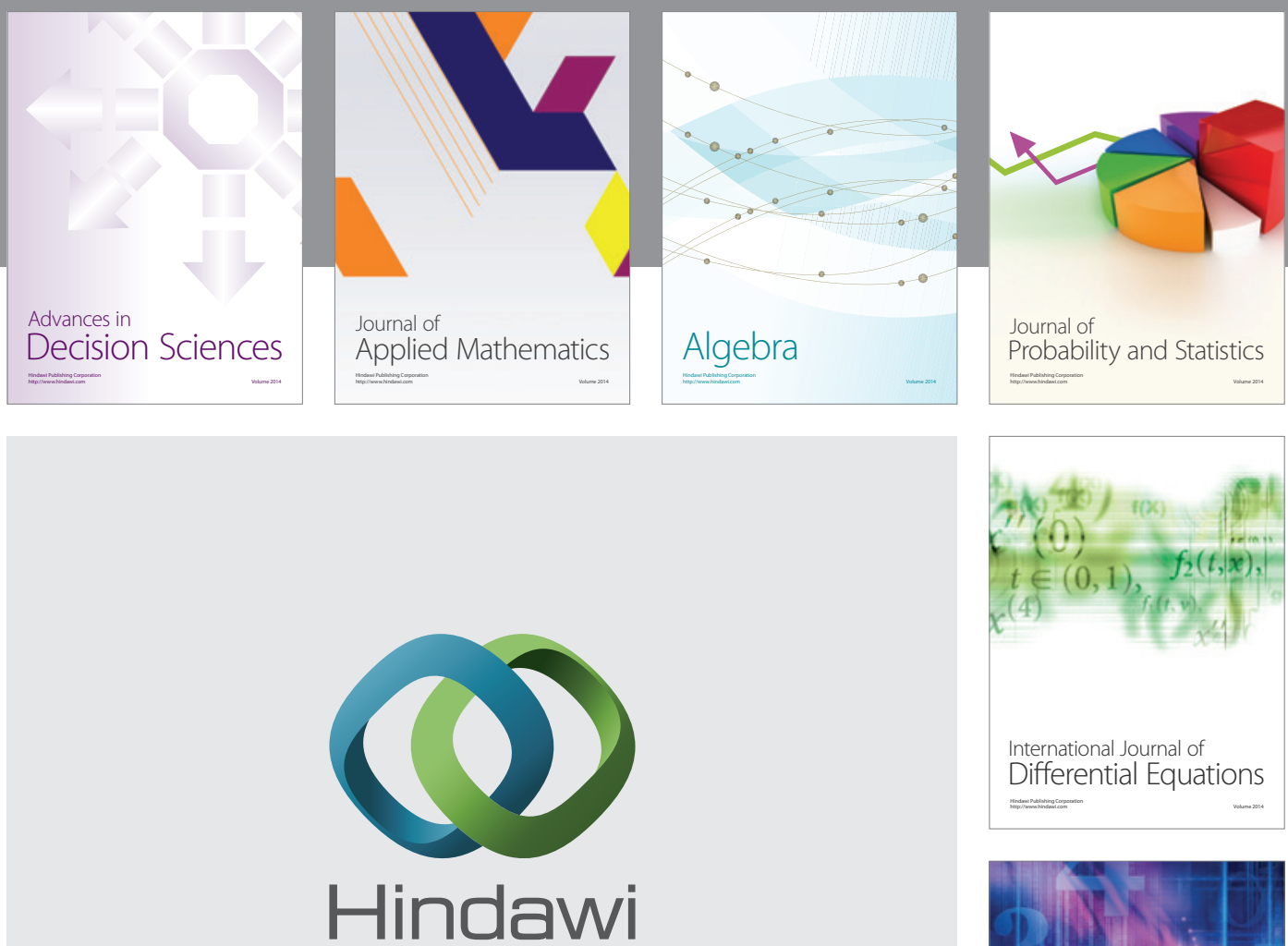

Submit your manuscripts at http://www.hindawi.com
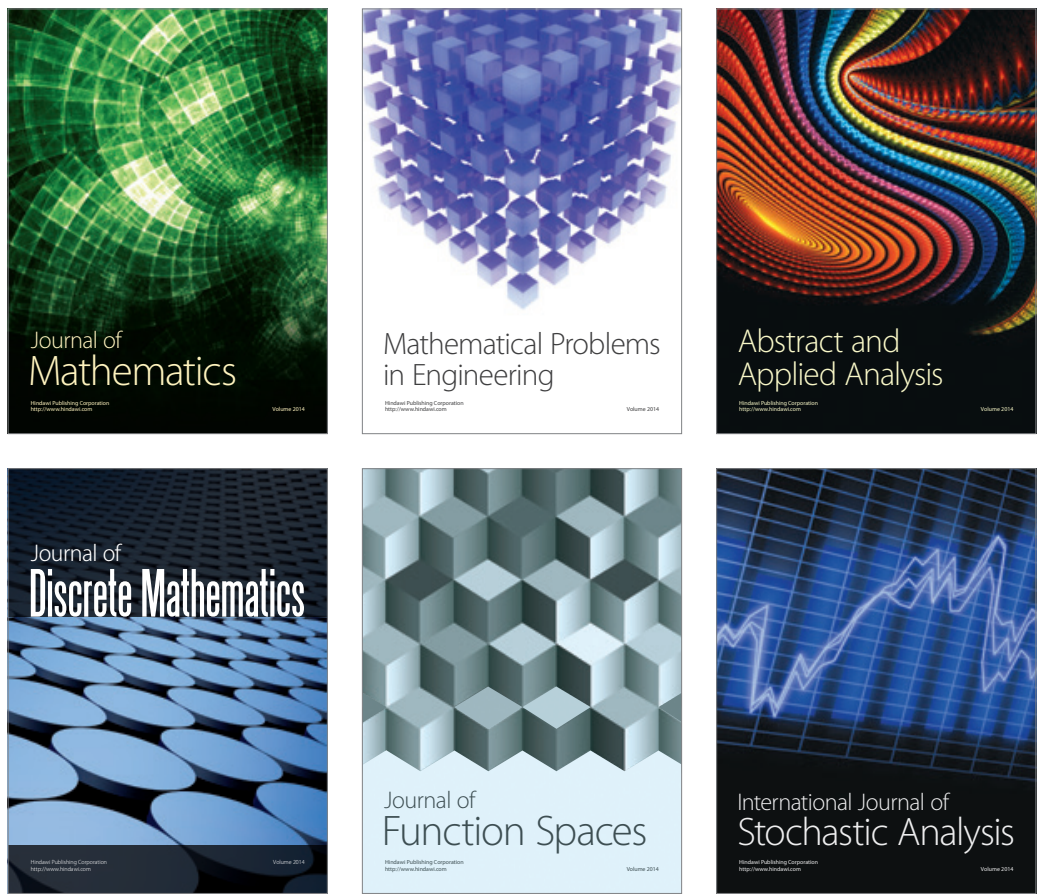

Journal of

Function Spaces

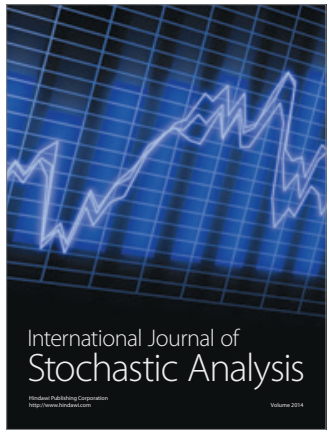

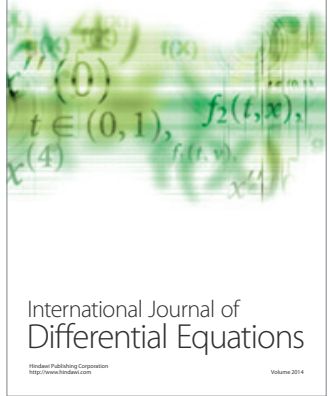
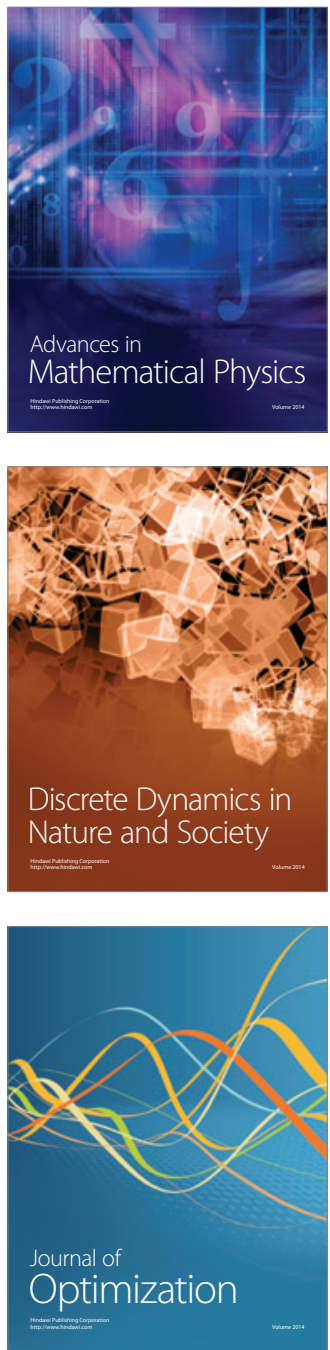